\title{
SUDDEN ONSET OF DOUBLE ELEVATOR PALSY: A RARE CLINICAL ENTITY
}

Sundip Shenoy ${ }^{1}$, Anitha Maiya ${ }^{2}$, R. Jayaram ${ }^{3}$, Venita J. Noronha ${ }^{4}$, Vasanth Kumar ${ }^{5}$

\section{HOW TO CITE THIS ARTICLE:}

Sundip Shenoy, Anitha Maiya, R. Jayaram, Venita J. Noronha, Vasanth Kumar. "Sudden Onset of Double Elevator Palsy: A Rare Clinical Entity". Journal of Evolution of Medical and Dental Sciences 2014; Vol. 3, Issue 05, February 03; Page: 1291-1297, DOI: 10.14260/jemds/2014/1982

\begin{abstract}
Double elevator palsy (DEP) currently known as Monocular Elevation Deficit is a rare condition characterized by restricted elevation of one eye in all positions of up gaze. Clinically it presents as a unilateral restriction of superior rectus (SR) and inferior oblique (IO). We present a case report of DEP in 3 year old boy who presented with sudden onset of DEP in right eye in our OPD. Very little information on acquired causes of DEP is available. Diagnosis, differential diagnosis and management are discussed and then the literature is reviewed.

KEYWORDS: DOUBLE ELEVATOR PALSY (DEP), MONOCULAR ELEVATION DEFICIT (MED), UPGAZE PALSY.
\end{abstract}

INTRODUCTION: Double elevator palsy (DEP) is a rare condition which was first described by White in 1942 and later by Dunlap. ${ }^{1}$ In DEP there is apparent paralysis of the elevators of one eye, the superior rectus and inferior oblique resulting in restricted elevation. DEP is actually a misnomer because true paralysis of the elevator muscles is seen only one-fourth of cases and mostly only one of the elevator muscles may be involved in certain cases. Hence DEP is better known as Monocular Elevation Deficit (MED) ${ }^{2}$.

CASE REPORT: A 3 year old school going male child presented to our clinic with complaints of sudden onset of downward vertical displacement of right eye of 15 days onset with chin elevation. His birth history was normal with normal Apgar score and no history of squinting (intermittent / manifest) in past 3 years. No history of stress, fever, trauma, measles or whooping cough or patching of eye. He is immunised upto age. Developmental milestones were normal. His ocular, medical and surgical history was unremarkable. No history of any systemic diseases or association with any congenital syndromes. Family history was negative.

General examination was normal. Old photographs were normal and showed no deviation of either eye.

On ocular examination, Visual acuity in both eyes was noted to be $6 / 6$ OU, not a spectacle wearer. Pupils were round regular and reactive. No nystagmus was noted. He presented with a head posture, mainly chin up position and head tilt to right. Visual field was normal by confrontation test. Cover uncover test revealed hypotropia of right eye seen in primary gaze associated with pseudo ptosis with brow elevation. No variation in lid position was seen during the course of the day. Neurological examination revealed intact Bell's phenomenon indicating supranuclear lesion in DEP.

Extra ocular muscle movement revealed a restriction of movement of right eyeball in up gaze (supraduction /supraversion) both in adduction and abduction pointing towards elevator deficit (Right SR and right IO) (PHOTO 2 and 6). All other movements were normal except for excessive movement of eyeball down, revealing right inferior rectus overaction (PHOTO 7). Buckling and tethering of central portion of lower lid was not seen which implies Inferior rectus restriction is 
absent. Krimsky and PBCT was done with base up prisms which confirmed vertical deviation of 10 pd. Worth's 4 dot test revealed no diplopia. There was no restriction of movement in left eye. Near point of convergence and accommodation was normal. FDT was negative.

Anterior segment was otherwise normal with normal fundus evaluation. Intra ocular pressure was normal. Atropine refraction revealed normal retinoscopic studies

\section{Investigations:}

Neurological examinations was normal.

CT of the brain and orbit revealed normal study.

DISCUSSION: In DEP, there is unilateral limitation of elevation in all horizontal orientations of the eye. When the patient fixates with the nonparetic eye (left), the paretic eye (right) will take a hypotropic position and the upper lid may be slightly ptotic. Fixation with the paretic eye (right) will cause a hypertropia of the nonparetic eye(left), and ptosis may disappear, provided the levator palpebrae is not involved (PHOTO 5). Patient may also complain of frequent upshoots of normal eye. Anatomical improbability that both superior rectus and inferior oblique are involved by single lesion suggests long standing SR palsy as the primary event with later spread of comitance leading to inferior oblique involvement. FDT is done to confirm any mechanical restriction of movement and was negative. Often there is chin up position to achieve binocular single vision. Bell's phenomenon is usually preserved and differentiates between supra nuclear and infra nuclear lesions. No risk of postoperative corneal exposure.

There are mainly two forms; Congenital and Acquired and has also been reported in twins ${ }^{3,4}$. Among the acquired forms one needs to exclude pineocytoma, polycythemia vera, vascular events and metastatic events. Possible differential diagnosis of DEP include blow-out fracture of the orbital floor, congenital or acquired fibrosis, endocrine myopathy, myasthenia gravis, skew deviation, Parinaud's syndrome, Browns syndrome, heavy eye syndrome, pineocytoma and 3rd nerve palsy. (TABLES 1A, 1B, 1C)

DIFFERENTIAL DIAGNOSIS OF DEP/MED

\begin{tabular}{|c|l|l|}
\hline 1. & \multicolumn{1}{|c|}{ BROWNS SYNDROME } & \multicolumn{1}{c|}{ Absence of elevation in adduction, FDT positive } \\
\hline 2. & ORBITAL FLOOR FRACTURE & $\begin{array}{l}\text { Monocular limitation of elevation with numbness of infra orbital } \\
\text { region and enophthalmos, FDT positive on elevation, X ray and } \\
\text { CT confirmatory }\end{array}$ \\
\hline 3. & $\begin{array}{l}\text { THYROID } \\
\text { OPHTHALMOPATHY }\end{array}$ & $\begin{array}{l}\text { Acquired limitation in elevation with eye signs and IR } \\
\text { involvement }\end{array}$ \\
\hline 4. & MYOSITIS & Limited EOM with signs of inflammation, FDT Positive \\
\hline 5. & $\begin{array}{l}\text { CONGENITAL MUSCLE } \\
\text { FIBROSIS }\end{array}$ & Bilateral ptosis, hypotropia, up gaze limitation \\
\hline 6. & HEAVY EYE SYNDROME & Seen in myopia \\
\hline \multicolumn{2}{|c|}{ TABLE 1A: RESTRICTIVE CAUSES } \\
\hline
\end{tabular}




\begin{tabular}{|l|l|l|}
\hline 1. & $3^{\text {rd }}$ NERVE PALSY & $\begin{array}{l}\text { Ptosis, eye in abducted position, } \\
\text { dilated pupil }\end{array}$ \\
\hline 2. & MYASTHENIA GRAVIS & $\begin{array}{l}\text { Diurnal variation of ptosis, } \\
\text { eye signs positive }\end{array}$ \\
\hline 3. & $\begin{array}{l}\text { CHRONIC PROGESSIVE } \\
\text { EXTERNAL OPHTHALMOPLEGIA }\end{array}$ & $\begin{array}{l}\text { Deafness, ptosis, retinal } \\
\text { degenerations, Ophthalmoplegia }\end{array}$ \\
\hline \multicolumn{2}{|r|}{ TABLE 1B: INFRA-NUCLEAR CAUSES }
\end{tabular}

\begin{tabular}{|c|l|l|}
\hline 1. & $\begin{array}{l}\text { PARINAUD'S/ DORSAL MID BRAIN } \\
\text { SYNDROME }\end{array}$ & $\begin{array}{l}\text { Light near dissociation, spasm of accommodation } \\
\text { and convergence, Colliers sign, Upgaze palsy }\end{array}$ \\
\hline 2. & SKEW DEVIATION & Rotatory nystagmus and Brain Stem lesions \\
\hline 3 & $\begin{array}{l}\text { SUPRANUCLEAR PARESIS } \\
\text { OF MONO OCULAR ELEVATION }\end{array}$ & $\begin{array}{l}\text { No vertical squint in primary position and downgaze. } \\
\text { No ptosis, normal Bell's and dolls eye movement. }\end{array}$ \\
\hline \multicolumn{2}{|c|}{ TABLE 1C: SUPRA NUCLEAR CAUSES } \\
\hline
\end{tabular}

Von Noorden ${ }^{5}$ attributed DEP to long-term paralysis of the superior rectus (SR) in the presence of a normally functioning inferior oblique (IO) muscle, indicating that the motor signs may be due to SR paralysis alone. Ziffer et al classified DEP into three subgroups, using scleral search coil technique for evaluating saccadic velocities into groups of IR restriction, complete or incomplete SR paralysis and supranuclear palsy ${ }^{6}$.

\section{INVESTIGATIONS:}

1. MRI/CT: Neurological and squint evaluation was discussed. CT normal

TREATMENT: There are different surgical treatments for DEP which reflects the various causative mechanisms ${ }^{7}$. Results are seen only in improvement of eye position in primary gaze with minimal improvement in elevation.

Treatment is generally based on carrying out the forced duction test (FDT).

If FDT is positive, inferior rectus recession is carried out and most patients recover satisfactorily.

In the absence of IR restriction, (forced duction test negative) surgical treatment comprises of the KNAPP PROCEDURE ${ }^{8,9}$. Here the entire tendon of both the medial and lateral rectus muscle is transferred to the side of superior muscle insertion. In transposition, as the 4 anterior ciliary arteries are sacrificed, a 6 month adaption time should be given before operating the third rectus to prevent anterior segment ischemia. In the absence of IR restriction, results are good. If the IR is restricted, the muscle has to recessed before or after transposition.

If vertical deviation in primary position is large, then IR recession with SR resection is done ${ }^{10}$. Recently, tucking of IR of normal eye is also done to remove residual hypotropia and pseudoptosis that may persist after the Knapp Procedure ${ }^{11 .}$

Therefore, the surgical procedure should be individualized for each case based on the etiology and mechanisms of involvement. 


\section{CASE REPORT}

SUMMARY: A case of sudden onset of Monocular elevation deficit /DEP (right eye) in a 3 year old boy with chin elevation and head tilt to the right is described with various etiologies and management.

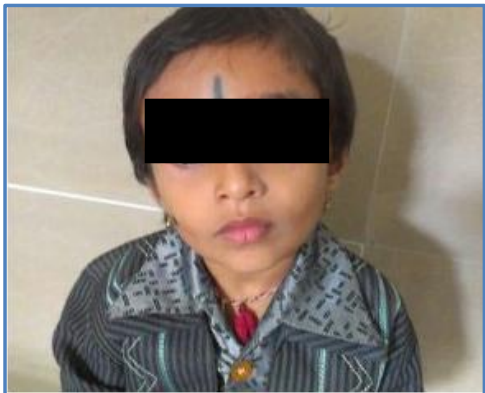

PHOTO 1: HEAD POSTURE (CHIN ELEVATION AND HEAD TILT TO RIGHT)

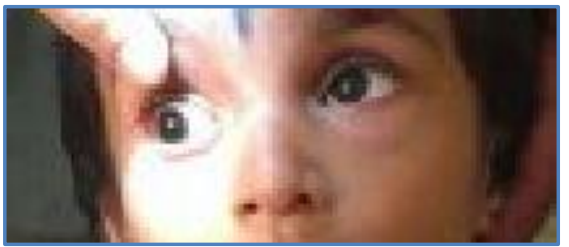

PHOTO 3: DEXTROVERSION

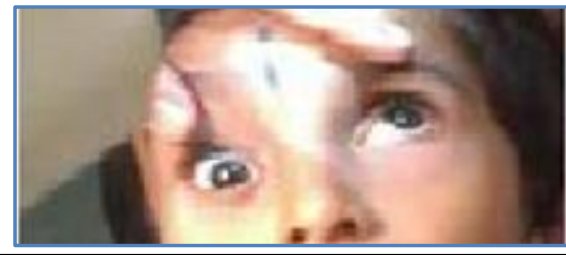

PHOTO 2: SUPRAVERSION SHOWING RESTRICTED UPGAZE ONLY IN RE
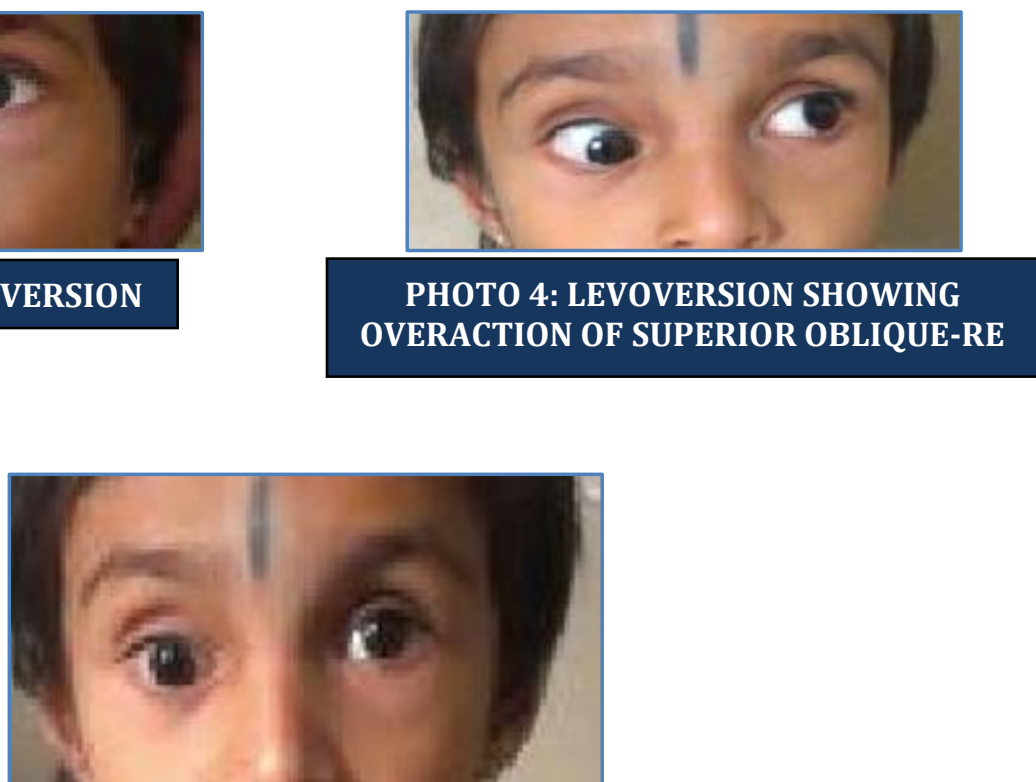

PHOTO 5: PRIMARY GAZE SHOWING HYPOTROPIA CORRECTED WITH PARETIC EYE FIXING (RIGHT EYE) AND CORRECTION OF PSEUDOPTOSIS

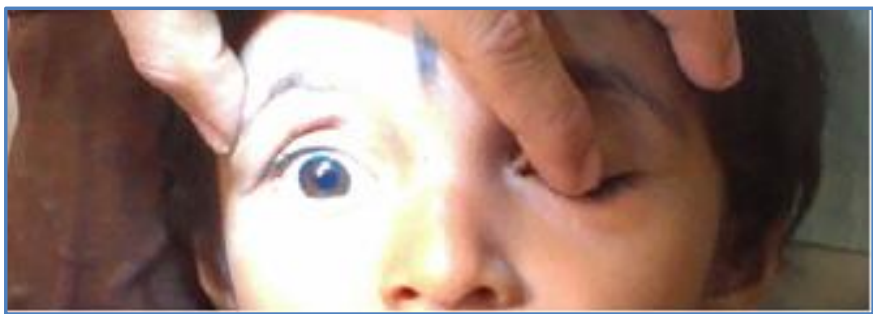

PHOTO 6: SUPRADUCTION RE SHOWING RESTRICTION OF UPGAZE 


\section{CASE REPORT}

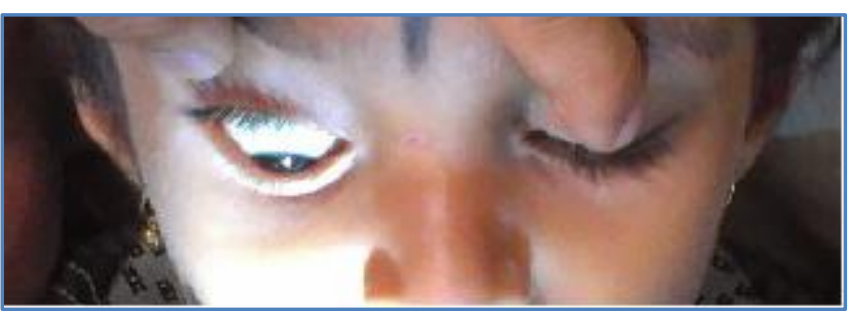

PHOTO 7: INFRADUCTION RE SHOWING OVERACTION OF IR

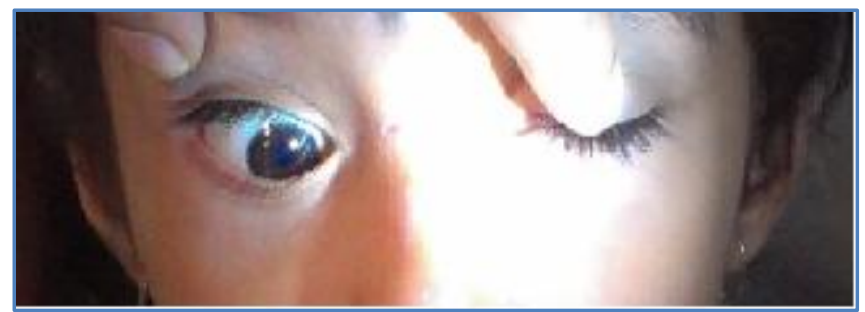

PHOTO 8: ADDUCTION RE

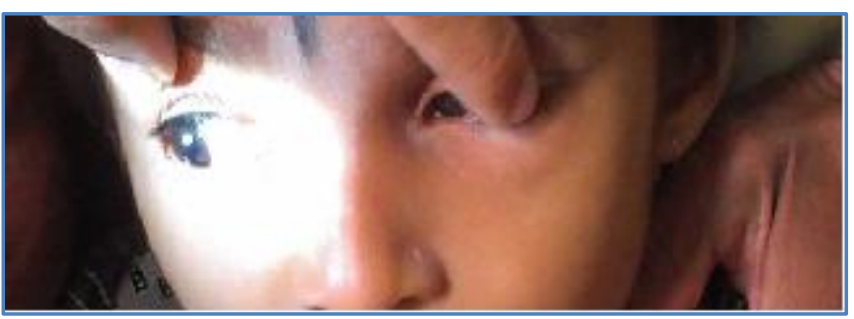

PHOTO 9: NORMAL ABDUCTION RE

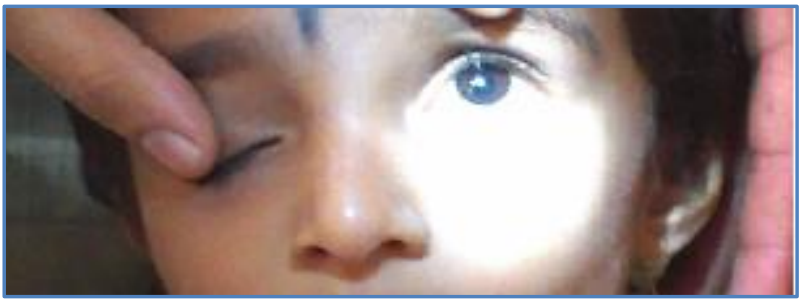

PHOTO 10: NORMAL SUPRADUCTION LE

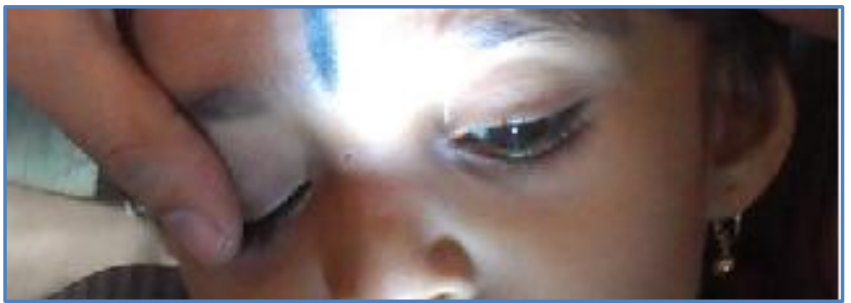

PHOTO 11: NORMAL INFRADUCTION LE 


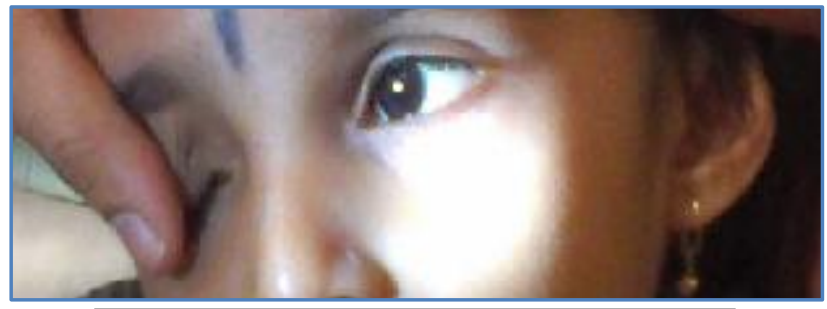

PHOTO 12: NORMAL ADDUCTION LE

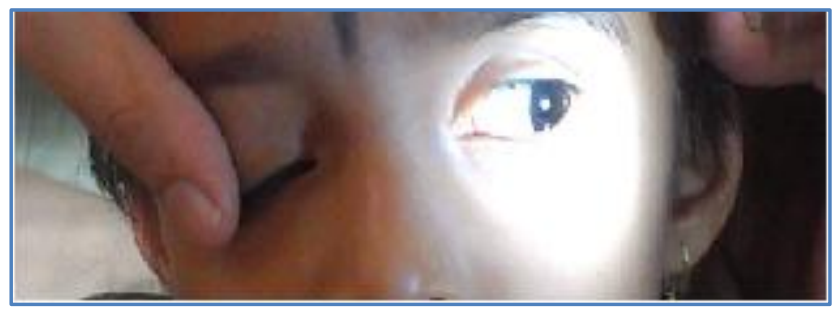

PHOTO 13: NORMAL ABDUCTION LE

\section{REFERENCES:}

1. Dunlap EA. Vertical displacement of horizontal recti; Symposium on strabismus transactions of the New Orleans Academy of Ophthalmology; St Louis: Mosby; 1971. pp. 307-329.

2. Kataria Sneha et al. Double Elevator Palsy (Monocular Elevation Deficit): An Update. Surgical Techniques in Ophthalmology. Strabismus Surgery (2011): 264.

3. Venkatesh Ramesh and H. Trivedi. Congenital Double Elevator Palsy. Bombay Hospital Journal 50.4 (2008).

4. Bagheri Abbas, Ramin Sahebghalam and Mohammad Abrishami. Double Elevator Palsy, Subtypes and Outcomes of Surgery. Journal of Ophthalmic \& Vision Research 3.2 (2008): 108.

5. Von Noorden GK. Binocular vision and ocular motility. 6th ed. ST Louis: Mosby; 2002.

6. Ziffer AJ, Rosenbaum AL, Demer JL, Yee RD. Congenital double elevator palsy: vertical saccadic velocity utilizing the scleral search coil technique. J Pediatr Ophthalmol Strabismus. 1992; 29:142-149.

7. Bagheri A., R. Sahebghalam and M. Abrishami. Double elevator palsy: a 10-year review of operated patients. Bina Journal of Ophthalmology 12 (2006): 81-88.

8. Bandyopadhyay Rakhi, Shashikant Shetty and P. Vijayalakshmi. Surgical outcome in monocular elevation deficit: A retrospective interventional study. Indian journal of ophthalmology 56.2 (2008): 127.

9. Yurdakul, Nazife Sefi, Seyda Ugurlu and Ahmet Maden. Surgical treatment in patients with double elevator palsy. European journal of ophthalmology 19.5 (2009): 697.

10. Rosenbaum AL. Clinical strabismus management. 1st ed. Philadelphia: WB Saunnders; 1999.

11. Samir, Ahmed and Ossama Hakim. A New Approach for Management of Monocular Elevation Deficiency. J Clinic Experiment Ophthalmol 2.136 (2011): 2 


\section{AUTHORS:}

1. Sundip Shenoy

2. Anitha Maiya

3. R. Jayaram

4. Venita J. Noronha

5. Vasanth Kumar

\section{PARTICULARS OF CONTRIBUTORS:}

1. Associate Professor, Department of Ophthalmology, Adichunchanagiri Institute of Medical Sciences, B.G. Nagara, Mandya, Karnataka.

2. Assistant Professor, Department of Ophthalmology, Adichunchanagiri Institute of Medical Sciences, B.G. Nagara, Mandya, Karnataka.

3. Professor, Department of Ophthalmology, Adichunchanagiri Institute of Medical Sciences, B.G. Nagara, Mandya, Karnataka.
4. $2^{\text {nd }}$ Year Post Graduate Resident, Department of Ophthalmology, Adichunchanagiri Institute of Medical Sciences, B.G. Nagara, Mandya, Karnataka.

5. $\quad 2^{\text {nd }}$ Year Post Graduate Resident, Department of Ophthalmology, Adichunchanagiri Institute of Medical Sciences, B.G. Nagara, Mandya, Karnataka.

\section{NAME ADDRESS EMAIL ID OF THE CORRESPONDING AUTHOR:}

Dr. Sundip Shenoy, FF-1, \# 44/2, Madhav Residency, Dollar Scheme, Nandini Layout, Bangalore - 560096.

E-mail: drsundipvision@yahoo.com

Date of Submission: 07/01/2014. Date of Peer Review: 08/01/2014. Date of Acceptance: 20/01/2014. Date of Publishing: 30/01/2014. 